\title{
The Impacts of the Energy Transition on Growth and Income Distribution
}

\author{
Giacomo Luciani
}

\section{The Impacts of the Energy Transition on Economic Growth and Income Distribution}

Two conflicting narratives are frequently heard in connection with the economic impact of the energy transition. The first has it that the transition is a great opportunity to revitalize economic growth and increase employment. The second, in contrast, estimates that objectives like reaching carbon neutrality by 2050, as pledged by the European Union, would be "too expensive." Which is right?

The question is supremely relevant for the political viability of the transition and the implementation of the Paris agreement. It is not by chance that environmentalists have consistently asserted that decarbonization is not only good for the environment, but also for the economy. This assertion promises benefits to all, including people living in regions that may not be greatly affected by global warming; and to contemporaries versus future generation, thus fundamentally improving the political appeal of the transition. If, instead, decarbonization entails an economic burden, and even accepting that this burden is likely much smaller than that which would derive from climate change, the question of the sharing of such burden, both internationally and intergenerationally, inevitably arises. As we know, there has, unfortunately, been substantial and persistent pushback from electorates in democratic countries towards decarbonization policies; and governments are not implementing measures capable of delivering the goals they are subscribing to. This must have something to do with perceived costs and benefits!

In the following pages, we attempt at disentangling the multiple contrasting effects that might be expected from the energy transition. It goes without saying that the net effect, resulting from the balance of such multiple contrasting effects, is extremely difficult or impossible to predict. It will surely very much depend on the specific

G. Luciani $(\bowtie)$

SciencesPo PSIA, Paris, France

e-mail: giacomo.luciani@sciencespo.fr 
characteristics of the economy facing energy transition, notably its current energy system, rate of growth of energy demand, available energy resources, and opportunities for decarbonization. All of these are extremely variable country by country. It will also greatly depend on the specific transition path pursued, and especially the intended speed of the transformation.

The question, it should be stressed, is not whether it is more appropriate to move speedily with the transition; it is not whether mitigation is preferable to adaptation. It is quite possible-indeed supported by majoritarian expert opinion-that adapting to climate change might be much more expensive that avoiding or limiting the same. Nevertheless, if mitigation has a net cost in terms of economic well-being, disposable income, and income growth, the question of how the burden should be distributed inevitably arises. Finding a consensus or compromise on burden sharing may be very difficult indeed, and the path to mitigation may therefore result politically too arduous.

The prominence of the issue of burden sharing is abundantly evidenced by the acrimonious debates in successive COPs, and the difficulty that the European Commission has experienced in pushing for the adoption of the goal of carbon neutrality by 2050 . Some member countries of the EU have much "cleaner" electricity systems, thanks to greater reliance on hydro and nuclear. Other member countries significantly rely on coal and consequently generate much larger emissions per kilowatt/hour. The Commission has proposed the creation of a Just Transition Fund aimed at taking some of the burden from the shoulders of the worst emitters and transferring it to countries with cleaner electricity systems. But to what extent is it acceptable that countries that have invested in cleaner sources early on should be called to contribute to the cost of cleaning the systems of countries that have resisted doing so? (And, in some cases, even opted to abandon nuclear, thus worsening the problem?)

\section{Three Definitions of GDP}

The discussion of the economic impact of the energy transition that is proposed in this chapter is organized around the definition of gross domestic product (GDP). GDP can be looked at in three different perspectives: from the point of view of production generation, of production use, or finally of production (income) distribution.

- From the perspective of production generation, GDP is defined as the sum of all value added generated in an economy in a given time:

$$
\text { GDP }=\Sigma \text { value added }+(\text { taxes }- \text { subsidies }) \text { on products }
$$

where value added is defined as the difference between all costs of production (excluding the remuneration of factors of production, capital, and labor) and the realized value of the final product (i.e., total sales revenue at producers' prices). 
- Alternatively, GDP can be viewed from the point of view of the utilization of production, and in this case it is equal to consumption plus investment (gross capital formation or GCF), plus exports minus imports:

$$
\mathrm{GDP}=\text { Consumption }+ \text { Investment }+ \text { Exports }- \text { Imports }
$$

Gross capital formation (investment) in turn is composed of substitution of obsolete production tools to maintain existing production capacity, plus addition of new tools to expand production capacity (the latter constituting net capital formation or NCF).

- Finally, GDP can be viewed from the point of view of the distribution of income, in which case it is equal to total wages plus total profits and interests, plus net government transfers (taxes minus income subsidies):

$$
\text { GDP }=\text { Wages }+ \text { Profits }+ \text { Taxes }- \text { Subsidies }
$$

All of the above is very relevant for our discussion, because the energy transition has implications for value added; for the allocation of income to investment rather than consumption; to the distribution of income between wages and profits; for taxes and subsidies; and finally for foreign trade. All of these implications must be spelled out and considered to achieve a thorough understanding of the impact of the transition on GDP and its growth.

GDP is a frequently criticized indicator. Indeed, some of the weaknesses of GDP are well known: in particular, only products and services that are commercialized, i.e., paid for, are included (except for government services, which are included at cost). There are plenty of subjectively very valuable products and services that we enjoy, and play a very important role in determining the well-being of each of us, and at the same time are not necessarily paid for, hence not included in GDP. Also, lots of public services that are provided for free are included at cost, independently of the outcome. Hence, alternative measures have been proposed and sometimes used, such as the Human Development Index (UNDP 2019) or either Gross or Net National Income. Each alternative has merits and demerits, but in the end GDP remains the most widely used and the best measure of "what money can buy." It is quite possible that a decline in GDP will allow you to conduct a happier life than before, but your money will still buy less than it used to.

\section{Pricing Emissions}

It is a widely accepted starting point that the economic cause of global warming is a market failure due to the fact that the cost of emitting $\mathrm{CO} 2$ and other greenhouse gases (GHGs) into the atmosphere is not borne by the emitter (Nordhaus 2013). No 
one has to pay for using the atmosphere, and rules for preventing corporations and individuals from emitting pollutants are mostly concerned with local or, at most, national atmospheric conditions. Until very recently, the emission of GHGs has not involved a cost for the emitter, thus creating a negative externality.

This interpretation assumes that in the absence of a cost for emissions, carbonintensive technologies will be more attractive than clean alternatives. According to a point of view which is more and more frequently expressed, some clean alternativesnotably non-dispatchable renewables - are becoming cheaper and cheaper, and soon will be, or are already absolutely preferable to carbon-intensive technologies even in the absence of the imposition of a cost for emissions. Such statements frequently ignore systemic costs arising from growing penetration of non-dispatchable renewables beyond a certain threshold (variously estimated at 35-50\%). But even ignoring the issue of systemic costs, if it were true that clean sources may become cheaper than fossil ones, the market would, we may say, be vindicated, and policies to promote clean technologies would not be needed, because the latter would prevail out of their own greater competitiveness. At most, the energy transition might be a matter of speeding up (at a cost) a process that is taking place anyhow. In the rest of the chapter, I assume that fossil sources remain mostly cheaper than clean ones: therefore, if no cost is charged for emitting GHGs, the market will not by itself bring about decarbonization and avoid climate change.

If the cause of excessive GHG emissions is a market failure due to negative externality, the remedy must be sought in correcting the functioning of the market by imposing the internalization of the cost of emitting GHGs. This is the well-established "polluter pays" principle, which translates into the need of imposing a cost on carbon emissions.

By definition, the emergence of a new cost associated with the production of goods reduces the value added which the economy generates. This is because, other things being equal, the new cost increases the total cost of production. As energy enters in the production of all goods, this means that all productive activities will be faced with an increase in production costs.

Furthermore, also the cost of utilization of a given good may increase (if emissions are linked to the utilization as well as production stage: e.g., producing an internal combustion engine car will cost more, and using it will also cost more). In this case, either the producer accepts a lower per unit sales price, which is unlikely, or demand for the product may decrease because of the increased cost to the consumer: in both cases the net result will be a reduction in total value added.

GDP is the sum total of all value added generated in an economy, hence introducing a cost for carbon must reduce it. This effect may be more or less important depending on the level of the newly imposed cost and the extent to which the economy depends on carbon-intensive production and/or consumption; but it will inevitably be there.

In fact, one may argue that the downsizing of GDP when the cost of carbon emissions is made explicit is the consequence of the failure of acknowledging this cost in earlier years, since the beginning of the industrial era. In this view, past estimates of GDP, that do not include externalities, are exaggerated, and the introduction of 
an explicit cost for carbon emissions is just a remedy to past miscalculation. Following this line of thinking, the World Bank has proposed a concept of adjusted national income, which estimates environmental depletion associated with valueadded generation, and not included as production cost; and corrects national income accordingly (Lange 2018).

The matter is further complicated by the time lag between damage to the environment and the emergence of the economic cost of such damage. We suffer today from emissions released by past generations over longer than a century; and future generations will suffer because of our emissions. The economic damage that emitting a ton of $\mathrm{CO}_{2}$ today entails will only be visible in the future, and depends on how much $\mathrm{CO}_{2}$ has been emitted in the past. Therefore, in fact we cannot internalize the externality by imputing as cost the present value of the future economic damage caused by an additional unit of emissions, because we have no precise idea of what this cost might be. We are, rather, imposing a price on carbon emissions in order to solicit a market response and achieve a reduction or elimination of emissions. This price then represents the opportunity value to the potential emitter of emitting one additional unit (ton of $\mathrm{CO}_{2}$ ): he will stop emitting only if the price is higher or equal to the benefit that he may derive from emitting one additional GHG unit.

The explicit addition of a previously hidden cost is the reason that most governments are reluctant to introduce carbon pricing, whether under the form of a carbon tax or of a price generated by an emission trading system. Governments frequently prefer to resort to regulation and administrative measures, whose cost is non transparent and not immediately predictable by those on whose shoulders it will fall. But this cost exists: it may manifest itself as a shift from a preferred technology to a less commercially attractive one, or accelerated obsolescence of the existing capital stock, but in all cases it will lead to a decline in value added, hence of GDP.

\section{Carbon Prices Are a Tax}

But how is a price imposed on carbon? It is out of acts of government introducing an emission trading system or a carbon tax (or a combination of the two). In one way or another, the imposition of a price for carbon emissions translates into revenue for the government, i.e., higher taxation. Although in theory the imposition of a price on carbon emissions is justified by the additional cost that these emissions are likely to impose on future generations, the proceeds do not accrue to some fund set aside for future generations, but to the government of today. This is important, because taxes on products appear with a positive sign in the GDP Eq. (1). If all that happens is that a price on carbon translates into higher tax revenue, the impact on GDP will be neutral: higher costs imposed on enterprises and/or consumers are compensated by higher revenue for the government. If this higher revenue is used to subsidize select productive activities (e.g., production of electricity out of renewable resources by way of feed-in tariffs, or purchase of solar PV panels through reimbursement of part of the cost) all that will happen is that the value added of producers paying the 
tax will be decreased to the benefit of producers receiving subsidies, and aggregate value added may not change.

This would be our conclusion if the purpose of carbon pricing were to raise revenue for the government. In fact, the purpose is to stimulate a change in the behavior of producers and consumers, i.e., induce them to change their production methods or consumption baskets, reduce emission, and ideally decarbonize completely. Thus, the real cost consists of the "distortionary" effect of the combination of taxes (either explicit or through an ETS) and subsidies. In most cases taxes on products are designed in such a way as to minimize distortionary effects on production: in our case the distortion is the desired outcome. The "distortion" may be for the better, but still entails deviating from maximization of producers' profits or consumers' satisfaction, hence a worsening of their condition.

\section{Consumption or Investment?}

Next, we need to discuss the impact of the transition on the allocation of income to consumption vs. investment, as described by GDP Eq. (2). From this point of view, the impact of the transition is a needed decline in consumption, and increase in investment.

All consumption of goods and services entails some demand for energy. Energy saving is unanimously identified as a key component of the necessary decarbonization process: we need to drive less, fly less, heat or air condition less, and so on. We may shift to more efficient machines (requiring additional investment) in order to maintain the same level of net service while reducing energy consumption (increasing energy efficiency), but very likely reduced energy consumption is part of the deal.

Improvements in energy efficiency are unanimously considered an essential component of the energy transition. The International Energy Agency estimates that 37\% of the difference between the Stated Policies and the Sustainable Development Scenario must be contributed by improved energy efficiency (IEA 2019, p. 79). Whether this is genuinely increased efficiency (i.e., less energy use for unchanged level of service) or simply reduced energy consumption (i.e., acceptance of reduced level of service) is not clear. Some transition optimists believe that humankind will be able to achieve expanded level of service with reduced energy use through extraordinary improvement in efficiency, but this cannot at all be taken for granted.

This points to the need for more investment. There is no progress possible toward decarbonization that does not require some form of investment. True, the energy sector always stood out as relatively capital-intensive, meaning that investment would in any case be necessary to satisfy growing demand or improve efficiency, even if we were to continue with emitting GHGs into the atmosphere; however, the decarbonization agenda entails even higher investment.

There are two main effects at work. The first is accelerated obsolescence of the existing capital stock. Physical assets with decades or years of technical life left in them will become stranded. This affects Net Fixed Capital Formation, which, as said 
earlier, is Gross Fixed Capital Formation (i.e., investment viewed as the sum total of buildings and machinery added to the production process) minus the replacement of worn-out capital from the existing stock. Accelerated obsolescence means that more of the new fixed capital added in a year will simply compensate for the retirement of existing capital, instead of contributing to the enlargement of productive capacity.

The second effect is an expected increase in the capital/output ratio, i.e., increased capital intensity. As mentioned, the energy sector has been relatively capital-intensive even before the need to decarbonize became established, but in a decarbonizing world it will become even more so. Almost all renewable energy sources are characterized by high initial investment costs and low subsequent operational costs. The latter are mostly maintenance costs, not directly related to the volume of production, while marginal costs may be nil or irrelevant.

In some cases, additional investment for decarbonization may even negatively affect production capacity, rather than the opposite. Think for example of carbon capture associated to a fossil fuel-based power plant: the process of capturing $\mathrm{CO}_{2}$ absorbs some of the electricity generated by the plant, so that by investing in carbon capture we are actually decreasing the net output of electricity from the plant. Of course, what is gained is the elimination or decrease of emissions, but the usefulness of the plant with respect to its main product, which is electricity, is decreased. Or consider the expected transformation of the car industry from internal combustion to electric engines: this requires huge investment on the part of the automobile manufacturers for the introduction of new models, of distributors or municipalities for the installation of recharging stations, of final consumers for buying new vehicles-and the end result is a mobility service which is somewhat more limited (because of range limitations or recharging times) or at most equivalent to what they enjoyed previously.

The macroeconomic impact of additional investment requirements may be larger or smaller depending on whether the country in question experiences stagnant or increasing energy demand. Where energy demand is stable or declining (as in the EU), the required investment is more likely to be in substitution of existing production capacity. In contrast, in an environment of rapidly growing energy demand relative decarbonization may be achieved by focusing on clean solutions for incremental energy production capacity, and the increase in investment requirements relative to a scenario of business as usual might be much more limited. In fact, there may even be situations in which investment in renewable energy sources may be easier, because production units are smaller and economies of scale not as important as for traditional technologies. Greater modularity may facilitate spreading investment over time and reducing the financial burden.

The shift from consumption to investment may under certain conditions justify the assertion that decarbonization will enhance growth rather than the opposite. Whether this is the case depends on the initial condition of the economy. If the economy is distant from an equilibrium of full employment of available resources, and savings exceed investment for lack of opportunities or inefficient intermediation of the financial sector, the emergence of new investment opportunities, especially if 
strongly supported by clear and consistent government policies, may facilitate a shift toward greater utilization of resources. But how likely might such a scenario be?

It may be argued that the European economy has in fact been far from full employment equilibrium ever since the financial crisis of 2008. Expansionary monetary policies have failed to stimulate either consumption or investment. In our capitalist economies, investment is justified by the expectation of profit, which ultimately is supported by consumer demand. In recent years, consumer demand in Europe has remained subdued because of uncertainty, and savings have exceeded investment. In the US, the situation is altogether different.

The transition requires increased investment even though consumption may not increase, or even decrease. If resources can be channeled towards investment to implement the transition, in the context of departure from consumerism, it is indeed possible that the economy moves towards fuller employment of all resources, including labor, thus resulting in an acceleration of growth. But is this a realistic expectation?

The answer largely depends on institutions and policies. The latter in particular need to be predictable and strong enough to solicit the desired response from investors. The profitability of investment for the transition must be clearly established and consistently supported for investors to take the plunge.

But even if the required new investment projects are demonstrably profitable, the relevant investors might not be able to invest. A main example is investment for energy savings, which to a large extent depends on decisions to be taken by millions of final consumers: the investors in this case may face limitations in financing the investment, or be put off by the generally long recovery periods, or simply not be aware of all available opportunities. Even for corporate investors, their balance sheets may not be solid enough to underpin large financial efforts. Certainly, venture capital may be available, and shareholders are ready to pay high prices for the shares of companies that promise a bright future, in contrast with the equity of old energy companies, which commands low valuations notwithstanding the high dividends paid. But the impression is that so far not enough of available savings have been channeled toward investment for decarbonization. In fact, the opposite is likely true: the uncertainty surrounding many an economic activity in a decarbonizing future increases investors' risk and discourages long-term investment.

This is all the more true if we move from the national to the global level. Globally, many investment opportunities in cleaner energy sources are to be found in countries with dubious or precarious governance, presenting a risk profile, which few investors are willing to undertake. Global decarbonization ideally entails a massive shift of financial resources from the industrial to the emerging countries, because there demand for energy is growing faster, and the deployment of renewable energy sources would in many cases be easier.

But in fact, we see very little of this shift taking place: energy projects that reach final investment decision are more easily geared to the development of hydrocarbon resources than to investment in renewables. According to the IEA, in the period 2014-18 out of total global average annual energy investment of 2 trillion US dollars (at 2018 prices), 1 trillion, or 50\%, went to fossil fuels without carbon capture and sequestration. Renewables for power generation and final uses attracted 435 billion 
dollars, and energy efficiency 238 billion (IEA 2019, p. 50). Implementation of the Agency's Sustainable Development scenario would require an increase of global average annual energy investment to upwards of 3.5 trillion dollar (IEA 2019, p. 93), with roughly halving of investment in fossil fuels and tripling of other investment functional to the transition. Institutional barriers to such massive expansion and redirection of investment should not be underestimated.

It is therefore not clear at all that the decarbonization drive may per se suffice to overcome the low-employment equilibrium which is found e.g. in the European Union or Japan. Considerably more muscular policies than those currently implemented would be needed to convince private actors to substantially increase investment. Given the limited fiscal space that most governments enjoy, increased investment cannot be supported primarily by government expenditure. The imposition of a high enough carbon tax, whose proceedings were channeled exclusively and rapidly into support for energy transition-related investment, may become a driver for private investment, but would entail depreciation of existing assets, and uncertainty negatively impacting on corporate and household propensity to invest.

The task of achieving zero or negative $\mathrm{CO}_{2}$ emissions requires a massive shift from consumption to investment, i.e., a further increase in the rate of savings over GDP, rather than simply efficiently channeling existing savings towards investment. We normally expect economies that devote more of their GDP to investment and less to consumption to grow more rapidly, because investment adds to the capital stock and expands the production possibility frontier. But the energy transition entails investment that is predominantly in substitution of existing productive capacity, and might even decrease rather than expand existing capacity. Thus, the pro-growth effect of a shift of resources from consumption to investment might be undermined by the acceleration in the obsolescence of the existing capital stock and the increase in the capital/output ratio that the energy transition requires.

The speed of the transition plays an important role in determining whether growth will be supported or undermined. Fast transition requires a larger shift from consumption to investment, and faster obsolescence of the existing capital stock; it is therefore less likely to be conducive to faster GDP growth. In all advanced economies, growth is driven by consumption: to compress consumption and shift to a model of growth led by investment independently of an expected increase in aggregate demand is a huge political-institutional task. This is implicitly recognized by proponents of very ambitious policies arguing in favor of something close to wartime mobilization, but then the required societal acceptance is far from being guaranteed.

\section{Exports and Imports}

Equation (2) describing the destination of GDP also includes external trade: exports are a possible destination together with domestic consumption and investment; and imports are a possible alternative way to satisfy domestic consumption and investment and must therefore be subtracted from GDP. 
Advocates of pioneering the energy transition frequently insist on the fact that early movers may acquire comparative advantage, which will support their exports in the future. Furthermore, all countries that are net importers of fossil fuels would see their imports relatively reduced. The energy transition is therefore depicted as potentially improving the trade position of a country, and in this way contributing to its economic prosperity.

This is a simplistic approach for more reasons than one. Firstly, it should be underlined that export are a destination of GDP alternative to consumption and investment, so increasing exports must be matched by decreasing consumption or domestic investment, something which may be difficult to achieve in a context in which consumption already must be compressed to make room for a significant increase in investment. Exports are useful as driver of economic growth when domestic aggregate demand is not sufficient to justify the existing pace of investment-as was the case in the early years of most economic booms, including China's. But the energy transition cannot be led by export demand - at most the cost of some machines might be reduced if economies of scale are available, and export demand on top of domestic demand facilitates the attainment of large enough production runs. Thus, we may say that the energy transition is facilitated in China (and in the rest of the world) thanks to the collapse in the cost of PV panels that Chinese producers have been able to achieve; but surely this has been due to massive domestic demand in conjunction to export opportunities. It is the low cost of production rather than being pioneers that facilitates exports.

As for decreased import demand for fossil fuels, this can indeed benefit growth (especially in energy import-dependent emerging countries), inasmuch as it frees resources which otherwise might need to be devoted to exports, and improves the solvability of the country. It may therefore facilitate attracting foreign investment, which is a crucial consideration for supporting the energy transition in emerging countries. However, it is not always the case that decarbonization will allow decreasing imports: in coal-producing countries such as China or India a needed shift from coal to natural gas may lead to increased rather than reduced demand for imports.

\section{Income Distribution}

So far, we have discussed the impact of decarbonization on the formation and use of GDP: we must now discuss income distribution, i.e., how decarbonization may affect the share of income accruing respectively to labor (wages) and capital (profit).

The distribution of income between labor and capital is determined by the capital/output ratio. As discussed earlier, the energy transition entails an increase in the capital/output ratio, because of a shift to more capital-intensive technologies and little net benefit of the required additional investment (i.e., more capital needed for the same output).

An increasing capital/output ratio automatically results in an increasing share of income accruing to capital, unless fully offset by falling returns on industrial 
investment or interest rates on borrowed capital. We do live in a world of historically low interest rates, but there is no evidence that corporations are ready to accept lower returns. In fact, the opposite is true, as the perception of risk has widely increased, and in the energy industry the perspective of decarbonization further increases risk. Thus, the increase in the capital/output ratio associated with the energy transition inevitably also determines a shift of income from labor to capital-i.e., a widening of inequality in income and wealth distribution.

It should be stressed that the energy transition in this case simply reinforces a trend that has been underway ever since the end of the Second World War, as argued by Piketty (2013). Thus, while we certainly cannot attribute exclusive responsibility for growing inequality to the energy transition, the fact that it adds to an unwelcome existing trend further hinders public acceptance.

This effect on income distribution must be compounded with the effect of the increasing cost of energy on different income groups. It is generally accepted that an increasing cost of energy has a regressive impact on income distribution because energy expenditure is a larger share of the budget of poorer households. In addition, households are expected to invest to minimize the added cost, e.g., in insulation of their homes or buying new electric vehicles, but the vast majority of households has no net savings and no borrowing power either. Thus, richer households can contain the added cost by engaging in investment, but poorer citizens simply must bear the brunt of the decarbonization agenda.

The above is true at the level of individual countries, but even more so at the global level. Although emerging countries may offer better opportunities for decarbonization-because it is easier to decarbonize where energy consumption is growing than where it is stagnant - and because of more favorable climate and environmental circumstances in some cases; nevertheless, the burden of a higher capital/output ratio will be felt universally. The poor in emerging countries are even less able to bear the burden of added energy costs - although at the extremely low level of consumption that they currently enjoy the difference may not be felt (if you rely on collecting wood for cooking and on a small generator for lighting). And the availability of investment finance is certainly critical for all emerging economies and chronically insufficient to meet all investment needs.

It is indeed difficult to see how global decarbonization may take place unless policies and institutions are put in place to facilitate the emerging countries' access to investment finance, which, however, also implies an added financial burden on the industrial countries and a further reason why income inequality in the latter may be expected to widen.

It is therefore not surprising that the energy transition agenda has been accompanied by demands for financial transfers from rich to poor countries; and proposals for the introduction of a carbon tax in industrial countries are accompanied by the suggestion that the proceedings should be entirely redistributed to citizens on an equal basis, so that poorer citizens may actually end up being better off.

There are, however, at least two major problems with coupling environmental and redistributive measures. The first is that the energy transition contributes to, but is not the only cause of growing income inequality. Why should the introduction of a 
citizens' income be funded in particular by the carbon tax? These two measures are logically separate and the only reason for coupling them is to facilitate the swallowing of the bitter pill — the carbon tax — with sugar coating — citizens' income. The second problem is that devoting the revenue from a carbon tax to redistribution, rather than in particular supporting investment functional to the transition, would reduce the effectiveness of the policy with respect to its environmental goal. It should be recalled that the carbon tax has the ambition of eventually disappearing when decarbonization will have succeeded - the sooner the better; it is therefore not an appropriate fiscal tool for addressing a problem that will remain long after decarbonization has succeeded.

\section{Employment}

It is normally asserted that the energy transition will generate millions of new jobs globally, and in this way benefit the countries engaging in it. The evidence proposed consists of an estimate of all jobs created directly or indirectly by transition-related projects.

It is certainly to be expected that the investment surge linked to the transition will generate jobs. At the same time, jobs will also be destroyed in some industries - this being a major deterrent from reducing reliance on domestically produced coal or discouraging the sale of IC vehicles. But we need to approach the issue at a macro rather than micro level, and ask whether a shift in the composition of aggregate demand from consumption to investment is likely to increase employment. The answer is not straightforward.

Consumption demand has been progressively shifting from goods to services. Some categories of services are indeed labor-intensive, and normally associated with the growing number of poor-quality low-paying jobs; at the same time, other services have witnessed a huge improvement in productivity thanks to the introduction of information technology, and the threat to employment arising from artificial intelligence is a major preoccupation. Jobs created by investment expenditure are on balance likely to require higher skills and be better paid than jobs in services, although generalizations are questionable in this case.

It should be underlined that, although employment creation is a constant preoccupation for politicians and governments, labor is a cost, which should in principle be minimized. There is constant tension between increasing productivity and full employment: the former should be maximized, preferably with no detriment for the latter, which is only possible if total production is growing in line with productivity. We have noted that the transition must be expected to lead to an increase in the capital/output ratio, which also means a decrease in the productivity of capital (output per unit of capital is the inverse of capital/output). Assuming that, other things being equal, employment will also grow for a given output is tantamount to saying that the productivity of labor (which is the ratio of output to employment, or output per worker) will also decrease. In other words, we are envisaging a decline in both the productivity of capital and of labor, i.e., a poorer world. 
Of course, productivity of capital and labor may increase in other industries and compensate for the loss of productivity in energy, but it is important to recall that increased employment in the energy industry, especially in countries where production is stagnant, is not per se a positive outcome.

The jobs created argument in support of the energy transition may very well turn out to be correct, but it is not clear that, other things being equal, it should be viewed as a net benefit. It does inevitably hide a decrease of productivity, which negatively affects total GDP and GDP per capita.

\section{Concluding Remarks}

If, as some claim, the energy transition were a win-win development, why should it be so difficult to implement? We need an energy transition and the cost of failing to make rapid progress in this respect may well be much higher than the cost of the energy transition itself, but there is a net cost to the energy transition both in terms of total available GDP and of its division among rich and poor.

If we want to make progress with the energy transition, it is necessary to acknowledge its cost and seek agreements on the division of the burden. Agreements are needed at the international level, between rich and poor countries, as well as domestically (within each country or the EU) between rich and poor citizens. For much too long proponents of the environmental agenda have bypassed this need and relied on the slogan that the transition is not only better for the environment, it is also better for the economy: unfortunately this may be true in the long term, but it is mostly not true in the short and medium term.

Governments have been searching for paths of lesser resistance, measures with limited costs, or non-transparent costs whose burden on each individual could not easily be predicted. This approach has largely failed: the share of fossil fuels on total global energy consumption has not decreased at all since the UN Framework Convention on Climate Change entered into force in 1994.

Imposing a sufficiently high price on carbon emissions is the only approach that is widely based enough to solicit the needed global response, but no government is ready to bite the bullet. The reason is clear: it is the one approach that most clearly would bring to the fore the cost of the transition (and hence create the greatest incentive to engage in it earlier rather than later). Governments keep on preferring ad hoc measures that provide only partial benefits and stimulate the search for loopholes.

The bipartisan US initiative to impose a significant carbon tax and redistribute the income of the same (CLC 2019) may be slowly gaining traction also in Europe, where a European Citizens' Initiative was launched in 2019 (EC 2019). However, the resistance of vested interests is strong and unlikely to fade away.

As is evident from our argument, the cost of the transition depends on the speed of it. Slowing down the energy transition will relatively minimize the losses connected to premature obsolescence of existing capital stock, facilitate the transfer of resources from consumption to investment, and allow technological progress to come up with 
better, more efficient solutions. It may also give time to our political systems to adopt policies for the redistribution of income and wealth-independently of the energy transition-which in recent decades have been largely undone in most democratic societies. Today we face underlying conflicts because of inequality and lack of social mobility; these are not caused primarily by the energy transition, but the latter ends up being the lightning rod that precipitates open conflict, so that the transition becomes politically unviable.

The reversal of the globalization process may lessen the pressure of international competition and its drag to the bottom, allowing governments greater latitude to engage in voluntaristic policies, including tackling inequality and climate change. But it could also lead to a loss of credibility for multilateral institutions, and lack of interest for a global coordinated approach, which is indispensible for avoiding catastrophic global warming. Global growth is likely to slow down anyhow, and with it the growth in energy demand. Possibly, this may give us more time to pursue the transition at a slower, less conflictual pace.

\section{References}

CLC (2019) Economists' statement on carbon dividends. Wall Street J

EC (2019) Commission Decision of 3.7.2019 on the proposed citizens' initiative entitled 'A price for carbon to fight climate change'; Brussels C (2019) 4973 final

IEA (2019) World energy outlook 2019, Paris

Lange (2018) Glenn-Marie, Quentin Wodon and Kevin Carey eds. The changing Wealth of Nations 2018. World Bank Group, Washington DC

Nordhaus (2013) William The Climate Casino. Yale University Press New York, London

Piketty (2013) Thomas Le capital au XXI siècle, Seuil Paris

UNDP (2019) Human Development Report 2019, New York

Open Access This chapter is licensed under the terms of the Creative Commons Attribution 4.0 International License (http://creativecommons.org/licenses/by/4.0/), which permits use, sharing, adaptation, distribution and reproduction in any medium or format, as long as you give appropriate credit to the original author(s) and the source, provide a link to the Creative Commons license and indicate if changes were made.

The images or other third party material in this chapter are included in the chapter's Creative Commons license, unless indicated otherwise in a credit line to the material. If material is not included in the chapter's Creative Commons license and your intended use is not permitted by statutory regulation or exceeds the permitted use, you will need to obtain permission directly from the copyright holder.

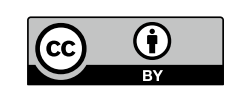

